\title{
Espacialidade Arquitetônica e Desempenho Térmico de Residências Contemporâneas em Clima Tropical Quente e Úmido
}

\author{
BRAGA, Nathália ${ }^{1}$ \\ SABOYA, Renato de \\ ORDENES, Martin
}

${ }^{1}$ Universidade Federal de Santa Catarina, Florianópolis, Brasil. nathbraga@hotmail.com

\section{Resumo}

O artigo em questão apresenta um estudo, conduzido através de ferramentas computacionais de simulação, o qual analisa a relação entre desempenho térmico (através do software EnergyPlus) e padrões espaciais (através do software Depthmap). A amostra de residências utilizada na pesquisa, representativa da arquitetura contemporânea de Natal/RN/Brasil, foi selecionada para que permitisse aanálise de como a distribuição dos cômodos em uma residência (sua espacialidade) poderia estar relacionada com o desempenho térmico de edificações naturalmente ventiladas, uma estratégia bioclimática bastante comum para regiões de clima tropical quente e úmido. Os resultados iniciais identificam uma tendência, a qual correlaciona alta integração, assim como conectividade, a menores custos em refrigeração.

Palavras-Chave: sintaxe espacial,arquitetura bioclimática, desempenho térmico de residências, ventilação natural, espacialidade.

\begin{abstract}
This paper presents a study, through simulation tools, of the relation between thermal comfort (on EnergyPlus) and spatial patterns (on Depthmap). The sample of dwellings analyzed, representative of the contemporary architecture from Natal-Brazil, was chosen in order to study how room distribution within a residence (its spatiality) can be related to thermal performance of natural ventilated buildings, a common bioclimatic strategy for tropical regions. Main results show that it was identified a tendency, which relates high integration, as well as connectivity, to low costs on refrigeration.
\end{abstract}

Keywords: space syntax, bioclimatic architecture, thermal performance in residential buildings, natural ventilation, spatiality. 


\section{Introdução}

É de conhecimento geral o fato de que a economia de energia em edificações é um requisito essencial nos dias de hoje, considerando as necessidades de um mundo mais sustentável, e um melhor equilíbrio natural. Dentro desse contexto, as edificações contemporâneas procuram melhorar suas relações com o meio ambiente, em busca de uma maior economia de energia e recursos naturais.

A pesquisa em questão é motivada pela ausência de estudos em desempenho térmico que igualmente considerem a questão da espacialidade nas edificações. Espacialidade, nesse caso, é entendida como a relação entre permeabilidade física e visual e a envoltória, assim como as consequências para a integração, legibilidade e apropriação de espaços internos. Será considerada a questão da análise da visibilidade espacial, conforme comentado por Turner (2003, p. 657): "Devemos utilizar a análise de visibilidade para falar sobre propriedades morfológicas do espaço construído, ou para falar acerca de como as pessoas se movimentam e interagem com o espaço visível, ou mesmo para descobrir a significância de certos objetos inseridos naquele espaço.".

A análise de tais aspectos espaciais permitiria um entendimento mais profundo acerca da "socialização", - qual possui um significado preciso na sintaxe espacial: "co-presença de pessoas em um espaço, respectivamente por acessibilidade física ou visual possibilitada pela natureza das fronteiras interespaciais as quais podem ser mais/menos permeáveis ao movimento, e mais/menos transparentes à visibilidade"(Holanda, 2011, p. 179). Hanson (1998) também explica que a manipulação da forma espacial pode enriquecer a experiência arquitetônica proporcionando socialização multifacetada; ou empobrecendo essa, articulando o ponto de vista de determinado ator ou ninguém em particular.

A pesquisa foi conduzida fazendo uso de software disponível na área de sintaxe espacial, Depthmap, e na área de simulação energética, EnergyPlus. A amostra de residências analisada na pesquisa, representativa da arquitetura contemporânea de Natal/RN, foi submetida a ambas as análises térmica e espacial com o objetivo de identificar a presença de padrões espaciais e como esses padrões estariam relacionados com o número de horas de conforto físico (térmico) obtidos durante o período de um ano, considerando o uso da ventilação natural. Estratégiabioclimática muito comum para garantir 0 conforto térmico em climas quentes e úmidos.

Desse modo, os autores da pesquisa esperam identificar tipos de espacialidade os quais trariam melhores soluções para residências bioclimáticas, considerando ambas as questões abordadas, social (espacial) e de desempenho térmico. Nessa perspectiva intenciona-se fazer uso de procedimentos de análise morfológica, dando ênfase à análise sintática do espaço através do trabalho intitulado Social Logic Space Theory (Hillier\& Hanson, 1984), assim como da análise de visibilidade do espaço (Turner et al, 2001). Ambos combinados com os procedimentos de simulação de desempenho térmico dos exemplos (projetos) selecionados.

Alguns estudos na área da sintaxe espacial considerando integração visual em espaços internos foram identificados pelos autores da pesquisa em questão (Beck \&Turkienicz, 2009; Lu, Peponis\&Zimring 2009), assim como na área de desempenho térmico de edificações naturalmente ventiladas no Brasil (Sorgato, 2009; Versage, 2009). Porém, é desconhecida a existência de estudos que combinem ambas as linhas de pesquisa.

Espera-se que ao final do estudo seja possível um melhor entendimento das influências mútuas entre distribuição espacial e desempenho térmico de residências naturalmente ventiladas, assim como um aumento do conhecimento acerca do desenho de novas edificações.

\section{Objetivo}

O artigo em questão tem como objetivo analisar as influências mútuas entre medidas da sintaxe espacial, à luz das teorias de Hillier\&Hanson (1984) e Turner (2001), e medidas de desempenho térmico, considerando horas de conforto físico (térmico) para o período de um ano, de um grupo de residências projetadas para clima tropical quente e úmido naturalmente ventiladas.

\section{Método}

Esse trabalho analisa basicamente medidas de sintaxe espacial através do software Depthmap e medidas de desempenho térmico através do software de simulação energética EnergyPlus. A análise se dará em três etapas: análise sintática dos modelos selecionados, gerando-se mapas e extraindo-se desses todos os dados relacionados a medidas de integração, conectividade, integração visual, índice de fechamento e profundidade do sistema; análise energética dos mesmos através de simulações, extraindo-se dados como Graus-hora $>26^{\circ} \mathrm{C}(\mathrm{GHr})$ anuais e taxas de troca de ar por hora (ach); e, em seguida,o cruzamento dos dados obtidos em busca de correlações entre os valores obtidos para cada medida, produzindo-se gráficos comparativos.

\subsection{Método}

Os As análises espaciais foram divididas em análise de visibilidade e análise de acessibilidade física, ou 
permeabilidade, ambas conduzidas através do software Depthmap e apresentadas em forma de Mapas VGA. Foram analisadas medidas de sintaxe espacial como conectividade (análise de visibilidade), integração $[\mathrm{HH}]$ (análise de permeabilidade) e integração visual $[\mathrm{HH}]$ (análise de visibilidade). Foram extraídas as médias dos valores de cada medida específica por zonas de modo a facilitar a interpretação dos dados gerados pelos mapas.

Cada edificação (projeto) analisada teve seu desenho simplificado em termos de possibilidade de movimentação e visibilidade internas. A análise de visibilidade somente considera as barreiras opacas à altura da visão do observador $(\mathrm{h} \approx 1,60 \mathrm{~m})$. Janelas $\mathrm{e}$ portas foram consideradas como sempre abertas para a análise de visibilidade. Entretanto, para a análise de acessibilidade somente as portas não foram consideradas barreiras. Tudo mais que dificultasse o movimento interno foi considerado como barreira na análise de acessibilidade. É também importante mencionar-se que os diferentes tipos de análise espacial relatados anteriormente somente consideraram os espaços internos da edificação e suas inter-relações.

Outro tipo de análise espacial, mais tradicional, fazendo uso de grafos foi também utilizado na pesquisa, permitindo futuras comparações com outros trabalhos realizados na mesma área. Esses são conhecidos como grafos justificadose são apresentados ao longo do artigo. Os grafos são construídos considerando os espaços como nós e o acesso direto entre eles como ligações. O ponto inicial dos sistemas, representados através dos grafos, é a porta de entrada de cada residência e cada espaço foicategorizado de acordo com seu uso como social, serviço, íntimo, circulação e jardim. O índice de fechamento foi igualmente utilizado, o mesmo é descrito por Hanson (1988) como a percentagem de espaços fechados sobre o número total de unidades convexas da edificação. Espaços fechados são definidos como espaços para intimidade como quartos, banheiros, suítes e lavabos.

Simulações de desempenho térmico conduzidas através do software EnergyPlus foram utilizadas para verificar o número de horas de conforto térmico durante o ano inteiro (Graus-hora/ano) através do uso da ventilação natural como estratégia bioclimática, bastante utilizada em climas quente e úmidos. Foram igualmente analisadas as taxas de troca de ar por hora (ach) de cada modelo analisado.Foram construídos modelos virtuais em 3-D para cada residência selecionada. Todos os aspectos construtivos utilizados nas simulações térmicas como aberturas, paredes, teto, cobertura, piso, pé-direito e proteções solares foram padronizados, uma vez que a intenção do estudo é analisar as variações de forma e suas consequências na espacialidade e no conforto térmico (Tabela 1). As dimensões das aberturas foram estabelecidas seguindo o mínimo requisitado pela legislação urbanística municipal de Natal/RN (Secretaria Municipal de Natal, 2009).

Foi utilizado em todas as simulações de desempenho térmico o arquivo climático anual(.epw) de Natal/RN (www.labee.ufsc.br). As janelas foram consideradas constantemente abertas durante todo o tempo da simulação (24h por dia), tendo em vista que, baseado em dadosclimáticos (.epw), o clima de Natal apresenta baixa amplitude térmica anual, ventos constantes (velocidade média anual variando entre 2 e $8 \mathrm{~m} / \mathrm{s}$ ) e umidade relativa quase sempre alta, com valores entre 70 e $90 \%$. Ainda com relação a isso,GOULART et al (1998) afirmam quea estratégia ventilação é a mais indicada em $83,5 \%$ dos casos de desconforto térmico para Natal/RN.

Tabela 1: Parâmetros utilizados nas simulações e seus respectivos valores.

\begin{tabular}{lc}
\multicolumn{1}{c}{ Parâmetros } & $\begin{array}{c}\text { Valores adotados para a } \\
\text { envoltória }\end{array}$ \\
\hline Clima & Natal/RN/Brasil \\
\hline $\begin{array}{l}\text { Percentagem de área ventilada em relação à área de piso }(\%)-\text { área de permanência } \\
\text { prolongada }\end{array}$ & 16 \\
\hline $\begin{array}{l}\text { Percentagem de área ventilada em relação à área de piso }(\%)-\text { área de permanência } \\
\text { temporária }^{2}\end{array}$ & 13 \\
\hline Absortância das paredes & 0,40 \\
\hline Transmitância térmica das paredes $\left(\mathrm{W} / \mathrm{m}^{2} \mathrm{~K}\right)$ & 2,59 \\
\hline Absortância da cobertura & 0,40 \\
\hline Transmitância térmica da cobertura $\left(\mathrm{W} / \mathrm{m}^{2} \mathrm{~K}\right)$ & 1,79 \\
\hline Transmitância solar dos vidros & 0,84 \\
\hline Absortância das proteções solares das aberturas & 0,50 \\
\hline
\end{tabular}

${ }^{1}$ Espaços como quartos, cozinhas, sala de jantar, sala de estar e escritórios.

${ }^{2}$ Espaços como banheiros, depósitos, área de serviço e lavabos. 
Com a análise do desempenho térmico de cada uma das residências intenciona-se verificar o número de Graus-hora (GHr) anuais para refrigeraçãoe as taxas de trocas por hora (ach), considerando o uso da ventilação natural, estratégia bastante comum na região para as quais as mesmas foram criadas. Por graus-hora anuais, como é utilizado nos procedimentos de etiquetagem brasileiros, entende-se: "O indicador do desempenho térmico da envoltória de edificações naturalmente ventiladas. É baseado no método dos graus-hora, o qual utiliza uma temperatura base, não levando em consideração temperaturas de conforto, consistindo em uma temperatura de referência para comparação. Neste RTQ, o indicador representa a soma de graus-hora calculados para uma temperatura base de refrigeração de $26^{\circ} \mathrm{C}$. Os cálculos são realizados através da temperatura operativa do ambiente." (Eletrobras/Procel.2009).

As cargas internas geradas pelos ocupantes, equipamentos domésticos e iluminação não foram consideradas nas simulações, tendo em vista, a observação da capacidade de cada edificação de manter um número aceitável de graus-hora (GHr) anuais e também considerando os inúmeros padrões de operação de uma residência, a partir do qual seria difícil estabelecer um que fosse representativo. As simulações free-floating, onde a ventilação é considerada constantemente ativa, foram realizadas considerando ambas as situações: janelas externas abertas e fechadas. Todas as janelas externas receberam proteções solares (venezianas) para melhora do desempenho considerando a alta radiação solar incidente. Todos os modelos foram orientados seguindo os projetos originais.

\subsection{A amostra}

A amostra consiste de residências projetadas para a cidade de Natal/RN, incluindoregião metropolitana. As edificações possuem área construída entre $150,00 \mathrm{~m}^{2}$ e $250,00 m^{2}$, o que as coloca em um padrão de construção de classe média a média alta. A grande variedade tipológica desse padrão assim como a acessibilidade aos projetos determinou a escolha. Além disso, os projetos coletados pertencem à produção arquitetônica contemporânea, do início da década de 2000 até os dias atuais. Foram coletados em escritórios de arquitetura da cidade de Natal/RN, sendo escolhidos a partir de amostragem aleatória simples.

Cinco residências foram selecionadas para a pesquisa em questão. Quatro delas, Casa 01, 02, 04 e 05, foram projetadas paraa cidade de Natal/RN, enquanto que a Casa 03 foi projetada pra a cidade de Parnamirim/ RN.As residências selecionadas possuem características básicas de uma típica casa brasileira. São todas formadas por sala de estar, sala de jantar, cozinha aberta, escritório, sala de TV, quartos, suítes, banheiros sociais (lavabos), banheiros privados e uma área de serviços. Algumas das residências possuem áreas sociais para receber visitantes externos como a Casa 05 (oficina e marcenaria).

Todas as residências foram projetadas por arquitetos profissionais, não necessariamente executadas.

\section{Apresentação e análise de dados}

A Figura 1 mostra como cada residência se configura e como foram zoneadas para as simulações.

\subsection{Casa 01}

Seguindo o que foi estabelecido no tópico "Método", mapas de permeabilidade (VGA) e mapas de visibilidade (VGA) foram criados para ilustrar as analises de visibilidade e acessibilidade da Casa 01.

Nota-se que no caso da Casa 01 o terraço, a entrada, e a sala de estar apresentam-se como os espaços mais integrados considerando a análise de permeabilidade (Figura 2).

De acordo com a análise de visibilidade, Figura 3, os espaços visualmente mais integrados e conectados da Casa 01 são ainda a sala de estar, o terraço e a entrada. Porém, a sala de jantar se torna mais conectada.

Para a análise térmica a Casa 01 foi zoneada de modo a facilitar as simulações. As duas zonas interconectadas foram nomeadas de Zona Íntima (ZI) e Zona Social (ZS).

Pode-se observar através da Figura 4que a Zonas Social (ZS)é aquela com menor número de graus-hora acima dos $26^{\circ} \mathrm{C}$, revelando-se a zona mais confortável da residência, considerando o número de horas analisadas para o período de um ano. Entretanto, a zona que demandaria o maior custo para refrigeração seria a Zona Íntima (ZI). É interessante notar que a diferença entre o desempenho de cada zona não é tão grande, considerando-se o caso no qual as janelas permanecem sempre abertas.

\subsection{Casa 02}

A análise de permeabilidade mostra (Figura 2) que nesse caso particular a entrada principal é o espaço mais integrado. Entretanto, um espaço íntimo como a circulação é relativamente bem integrado ao restante da residência.

A análise de visibilidade (Figura 3) também segue as mesmas estratégias utilizadas paras os casos anteriores. Porém, uma vez que a atual residência possui mais de um pavimento, as conexões (escadas) entre eles são igualmente consideradas. 
Figura 1: Plantas baixas das residências com suas respectivas zonas e orientações.

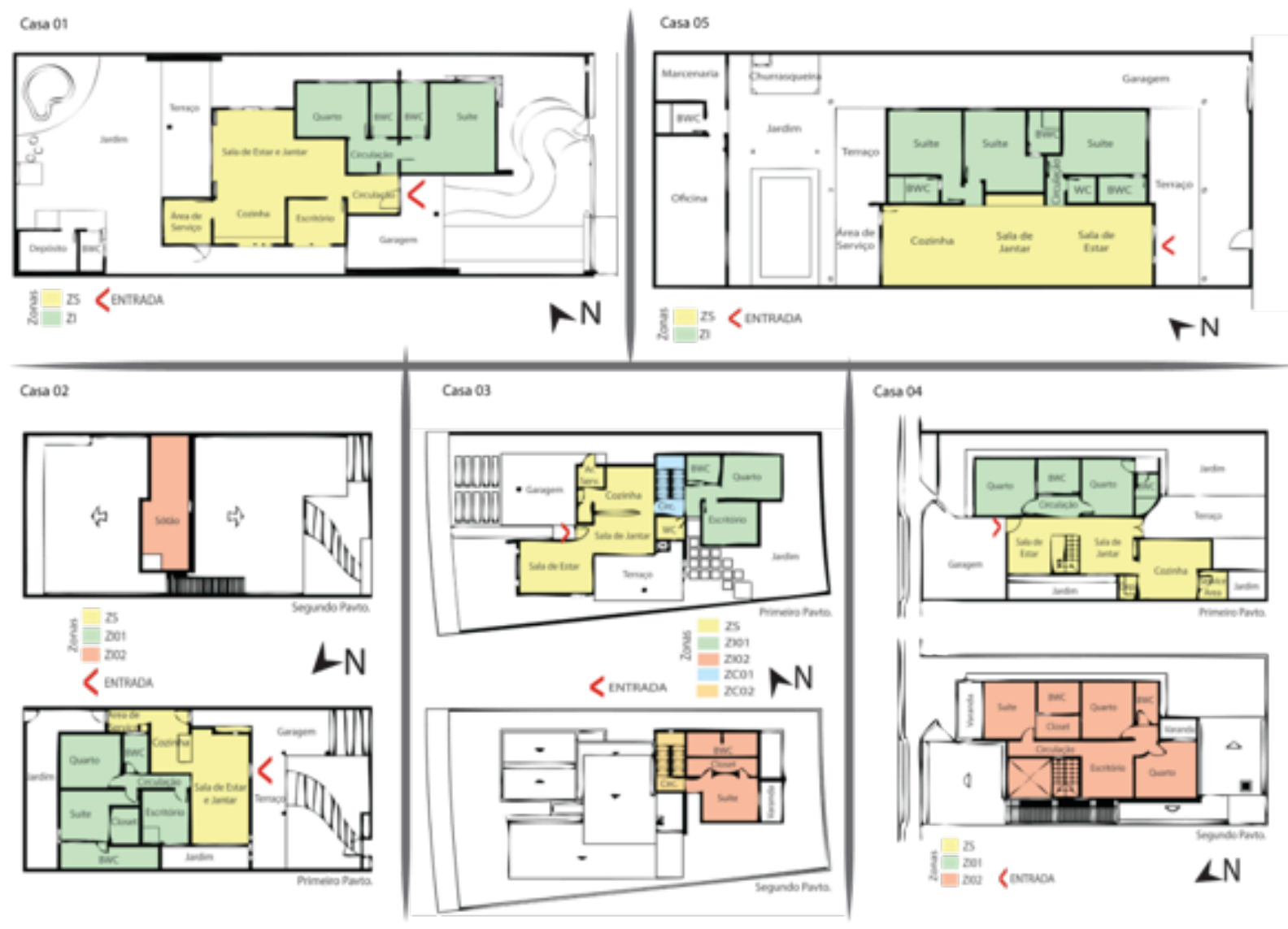

Figura 2: Mapas VGA de integração para cada residência considerando a análise de permeabilidade com seus respectivos valores de graus-hora $>26^{\circ} \mathrm{C}$ por zona, para a situação na qual as janelas permanecem sempre abertas.

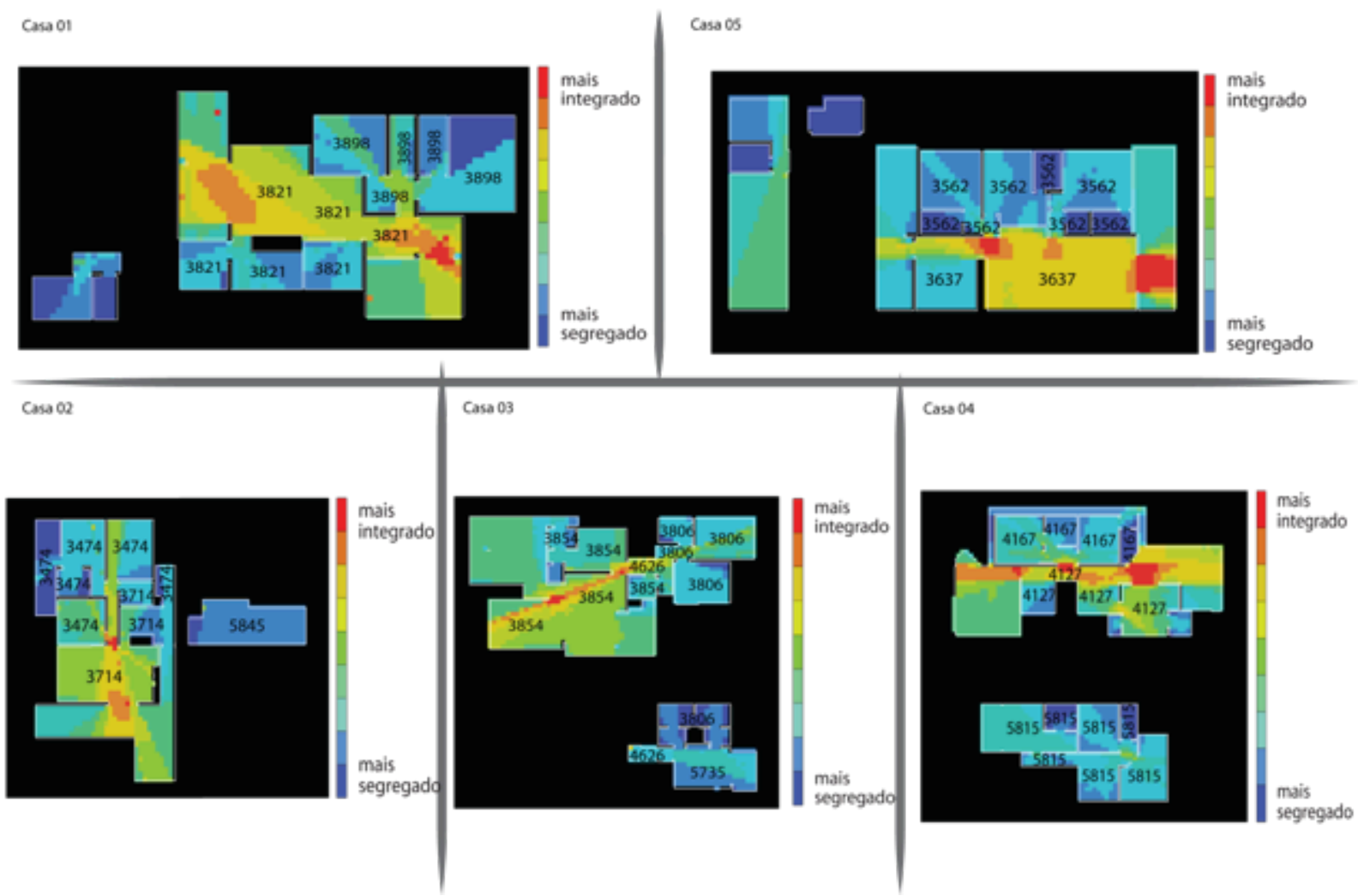


Figura 3: Mapas VGA de conectividade para cada residência considerando a análise de visibilidade com seus respectivos valores de graus-hora $>26^{\circ} \mathrm{C}$ por zona, para a situação na qual as janelas permanecem sempre abertas.

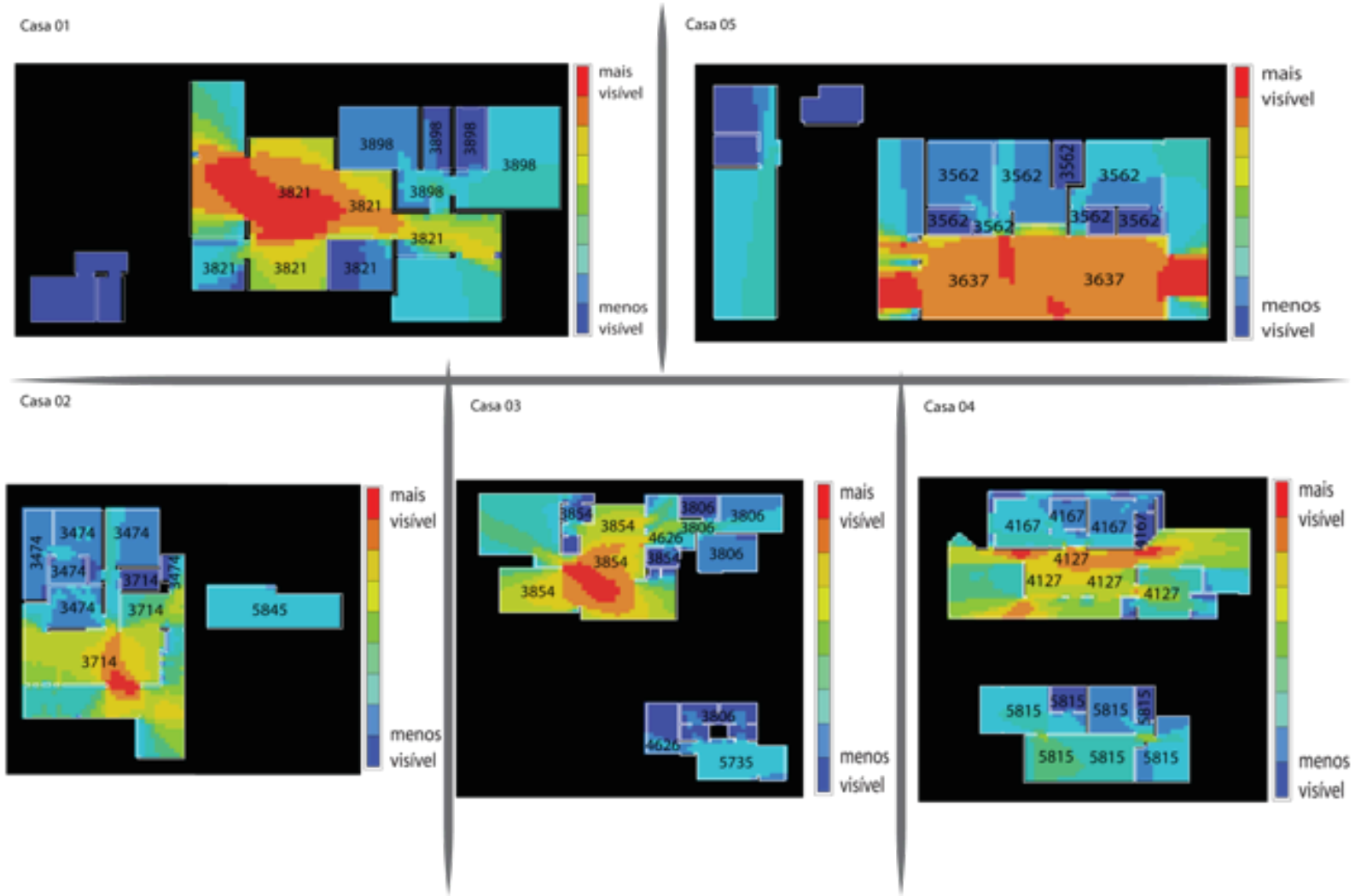

Os espaços visualmente mais integrados e conectados dessa casa em particular são, como nos casos anteriores, os espaços sociais. Essa situação é intensificada na sala de jantar localizada no pavimento inferior. É interessante notar que a circulação, supostamente um espaço íntimo, é também relativamente bem integrada visualmente ao restante do sistema.

Para a análise do desempenho térmico a Casa 02 foi zoneada em três zonas interconectadas tais como Zona Íntima 01 (ZI01), Zona Íntima 02 (ZI02) e Zona Social (ZS).

Pode ser observado através da Figura 4que a Zona Íntima 01 (ZI01) é aquela com o menor número de graus-hora acima dos $26^{\circ} \mathrm{C}, 3474$ horas. Porém, a zona que demandaria os maiores custos para refrigeração é a Zona Íntima 02 (ZI02), com um total de 5845 horas acima dos $26^{\circ} \mathrm{C}$. A Zona Social (ZS) apresentou 3714 horas de desconforto acima dos $26^{\circ} \mathrm{C}$. Para o caso onde todas as janelas são mantidas sempre abertas.

\subsection{Casa 03}

É observado através da analise de permeabilidade ilustrada pela Figura 2que nessa casa em particular, a sala de jantar, a sala de estar e parte do terraço são os espaços mais integrados e conectados. Os banheiros e quartos são os ambientes mais segregados, conforme esperado.
Foi observado através de análise de visibilidade (Figura 3) que os espaços mais integrados e conectados da residência em questão são a sala de jantar e parte do terraço. A cozinha e a circulação do pavimento inferior são visualmente bem integradas.

Para a análise do desempenho térmico a Casa 03 foi zoneada em cinco zonas interconectadas como Zona Íntima 01 (ZI01), Zona Íntima 02 (ZI02), Zona Social (ZS), Zona de Circulação 01 (ZC01) e Zona de Circulação 02 (ZC02).

Observa-se através da Figura 4que a Zona Íntima 01 (ZI01) é aquela com o menor número de graus-hora acima do $26^{\circ} \mathrm{C}, 3806$ horas. Entretanto, a zona a qual demandaria os maiores custos em refrigeração é a Zona Íntima 02 (ZIO2), com um total de 5735 horas acima dos $26^{\circ} \mathrm{C}$. Nesse caso, considerando-se as janelas da residência sempre abertas.

\subsection{Casa 04}

Observa-se através da análise de permeabilidade, ilustrada pela Figura 2, que nessa residência a circulação social e o terraço posterior são os espaços mais integrados. A cozinha também se encontra um pouco mais integrada que o restante dos ambientes.

Através da análise de visibilidade (Figura 3) observase que os espaços mais integrados da casa são a sala de jantar, a circulação social, as salas de estar e o terraço posterior. Já os mais conectados são a 
circulação social, a entrada principal e o terraço posterior.

Para a análise do desempenho térmico da Casa 04 a mesma foi zoneada em três zonas interconectadas, as quais são: Zona Íntima 01 (ZI01), Zona Íntima 02 (ZIO2) e Zona Social (ZS).

Observa-se através da Figura 4que a Zona Social (ZS) é aquela com o menor número de graus-hora acima dos $26^{\circ} \mathrm{C}, 4127$ horas. Entretanto, a zona a qual demandaria os custos mais altos em refrigeração é a Zona Íntima 02 (ZIO2), com um total de 5815 horas acima dos $26^{\circ} \mathrm{C}$. Nesse caso, considerando apenas o caso em que as janelas se mantêm sempre abertas.

\subsection{Casa 05}

Observa-se através da análise de permeabilidade ilustrada pela Figura 2que, no caso dessa residência, a sala de estar, a sala de jantar e o terraço frontal são os espaços mais integrados.

Já através da análise de visibilidade, Figura 3, observase que os espaços mais visualmente integrados da casa são a sala de jantar, a cozinha, e o terraço posterior. Os espaços mais conectados são ambos os terraços frontal e posterior.

Para a análise do desempenho térmico, devido à sua simplicidade projetual, a Casa 05 foi zoneada em duas zonas interconectadas nomeadas como Zona Íntima (ZI) e Zona Social (ZS).

Observou-se através da Figura 4que a Zona Íntima (ZI) é aquela com o menor número de graus-hora acima dos $26^{\circ} \mathrm{C}, 3562$ horas. Porém, a zona que demandaria os maiores custos para refrigeração é a Zona Social (ZS), com um total de 3637 horas acima dos $26^{\circ} \mathrm{C}$. Fica claro que a diferença entre 0 desempenho de ambas as zonas não é tão significante, considerando o caso no qual as janelas são mantidas sempre abertas.

\section{Discussão dos Resultados}

Observa-se que a Casa 05, a qual possui a Zona Social com os maiores valores de integração e conectividade é também o projeto que obteve o menor número de graus-hora $>26^{\circ} \mathrm{C}$. Por outro lado, a Casa 03 possui o pior desempenho térmico. A mesma apresenta valores de integração e conectividade, na Zona Social, similares aos da Casa 05, porém, as demais zonas apresentam valores inferiores, Figura 4 e Figura 5.
Figura 4: Média de graus-hora $>26^{\circ} \mathrm{C}$ por zona para ambas as condições, janelas sempre abertas ou sempre fechadas.

\section{Média de graus-hora $>26^{\circ} \mathrm{C}$}

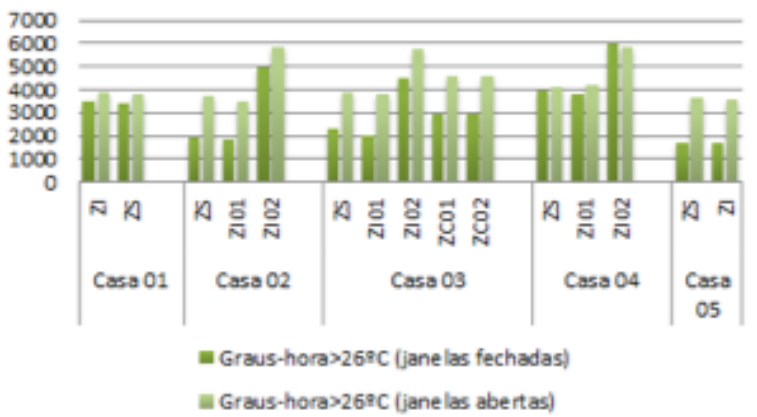

Figura 5: Média dos valores de integração por zona para ambas as análises de permeabilidade e visibilidade.

\section{Integração Média (VGA)}

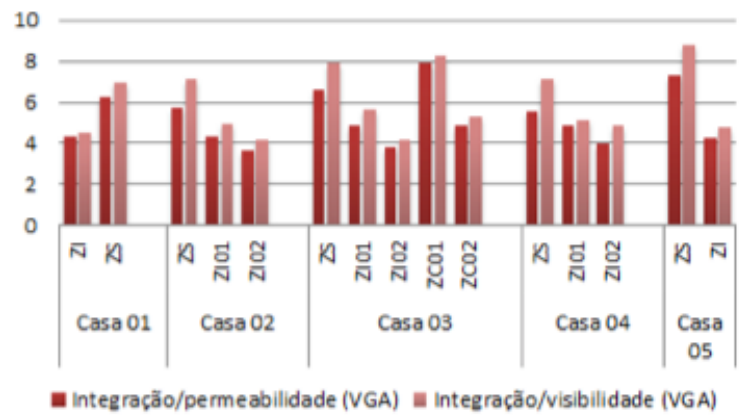

Enquanto assimulações de desempenho térmico revelam a Casa 05 como a mais confortável, e com o design mais compacto, a mesma também apresenta um dos valores mais baixos para o índice de fechamento. Por outro lado, a Casa 03, um dos modelos com o maior número de graus-hora $>26^{\circ} \mathrm{C}$, possui o segundo maior valor para o índice de fechamento, assim como uma média de taxa de trocas de ar anual baixa.

Desse modo é identificado um padrão que relaciona baixo índice de fechamento, alta integração e alta compacidade com melhor desempenho térmico. Assim como também relaciona maiores Trocas de ar, ou infiltração, com menores Índices de fechamento (Figura 6 e Figura 7).

Figura 6: Média anual das taxas de troca de ar (ach) por zona.

\section{Taxas de trocas de ar (ach)}

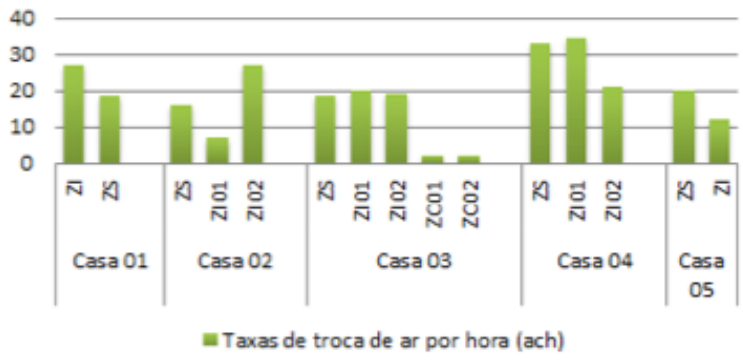


Figura 7: Índice de fechamento por casa.

\section{Índice de fechamento}

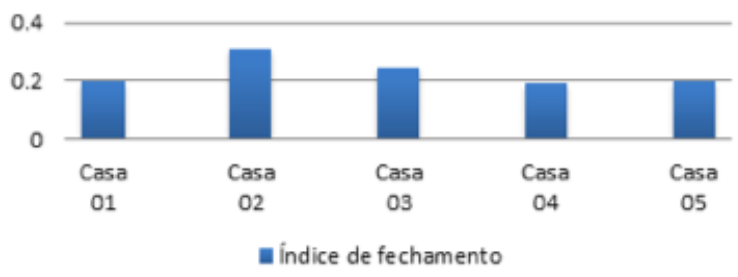

Sistemas mais compactos possuem menos superfícies externas expostas e, desse modo, menos troca de calor com o exterior. Esse padrão é observado na Casa 01, a qual possui desenho mais compacto e índice de fechamento similar à Casa 05 e um desempenho térmico razoável, assim como índice de trocas de ar razoável.Figura 8 e Figura 9 mostram essa relação entre índice de fechamento, Graus-hora e trocas de ar de modo mais detalhado.

Figura 8: Valores de índice de fechamento versus graus-hora $>26^{\circ} \mathrm{C}$ por zona para a condição na qual as janelas permanecem sempre abertas.

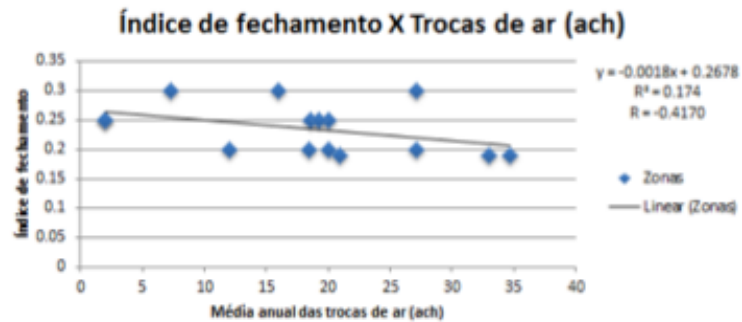

Figura 9: Valores de índice de fechamento versus taxas de troca de ar anual por zona.

Integração X Graus-hora $>26^{\circ} \mathrm{C}$

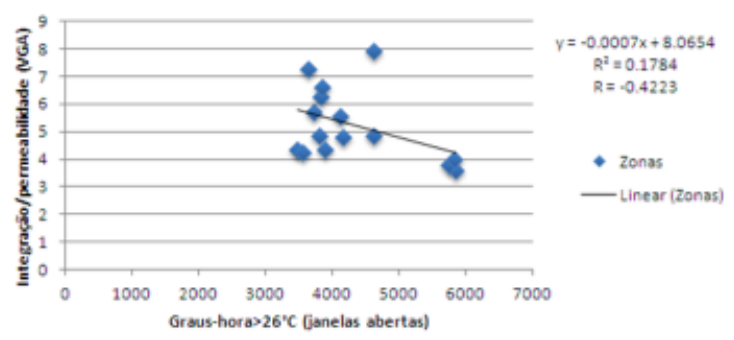

A correlação encontrada entre os valores de Índice de Fechamento versus a média anual das taxas de troca de ar (ach) é -0.42, ou seja, mediana. Outros valores completamente diferentes foram encontrados entre valores de Índice de Fechamento e graus-hora $>26^{\circ} \mathrm{C}$, essas são 0.10 (janelas sempre abertas), correlação muito fraca, e -0.23 (janelas sempre fechadas), correlação igualmente fraca.

A relação entre conectividade visual, integração e desempenho térmico é mais bem ilustrada entre a Figura 10 e a Figura 11.
Figura 10: Valores de integração (permeabilidade) versus graus-hora $>26^{\circ} \mathrm{C}$ por zona para a condição na qual as janelas permanecem sempre abertas.

Índice de fechamento $X$ Graus-hora $>26^{\circ} \mathrm{C}$

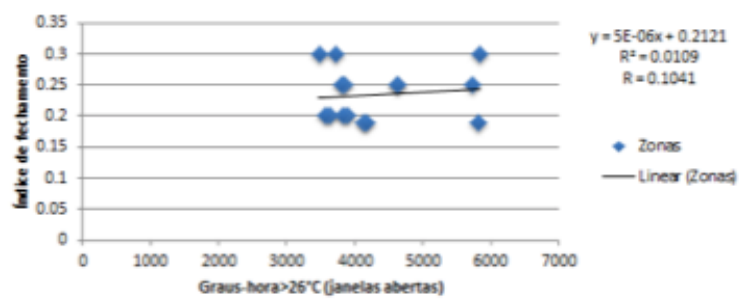

Figura 11: Valores de conectividade (visibilidade) versus graus-hora $>26^{\circ} \mathrm{C}$ por zona para a condição na qual as janelas permanecem sempre abertas.

Conectividade $X$ Graus-hora $>26^{\circ} \mathrm{C}$

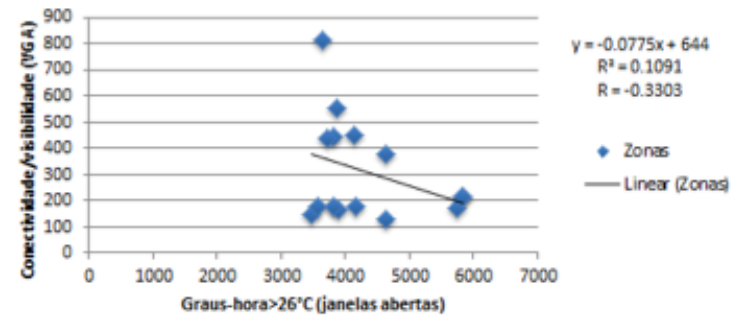

As correlações encontradas entre os valores de Integração (permeabilidade) e Graus-hora $>26^{\circ} \mathrm{C}$ são -0.43 (janelas sempre abertas) e -0.42 (janelas sempre fechadas), ou seja, negativas e medianas, porém, dentre as mais altas de toda a pesquisa. Para conectividade (visibilidade) versus Graus-hora $>26^{\circ} \mathrm{C}$ foi encontrada a correlação de -0.33 (janelas sempre abertas) e -0.30 (janelas sempre fechadas), valore mais fracos que os da integração (Figura 10 e Figura 11).

É importante notar-se que o desempenho térmico dos modelos melhorou, especialmente para as casas 02 , 03 e 05, quando as janelas externas foram consideradas fechadas durante todo o tempo da simulação, Figura 4. A partir desse resultado, pode-se concluir que manter as janelas fechadas durante todo o tempo da simulação, nesses casos, é melhor do que o que é feito em Natal. Porém, ambas as análises (janelas sempre abertas ou fechadas) seguem o mesmo padrão de distribuição de desempenho térmico por zona. E também se deve atentar para o fato de que cargas térmicas geradas por ocupantes não são consideradas.

Através dos grafos justificados foi possível observar que ambas as Casas 01 e 05 são os sistemas mais rasos e esses são distribuídos em seis níveis de profundidade. É importante notar que quanto mais profundo o sistema é, menores seus valores de integração (RRA) tendem a ser, Figura 12.

Considerando as profundidades dos sistemas de ambas as residências com um único pavimento (Casa 01 e Casa 05) comparadas com outras de dois pavimentos, observa-se que quanto mais profundo o sistema, maior é o número de graus-hora $>26^{\circ} \mathrm{C}$ que esse apresenta. 
Figura 12: Grafos justificados para cada sistema configuracional.

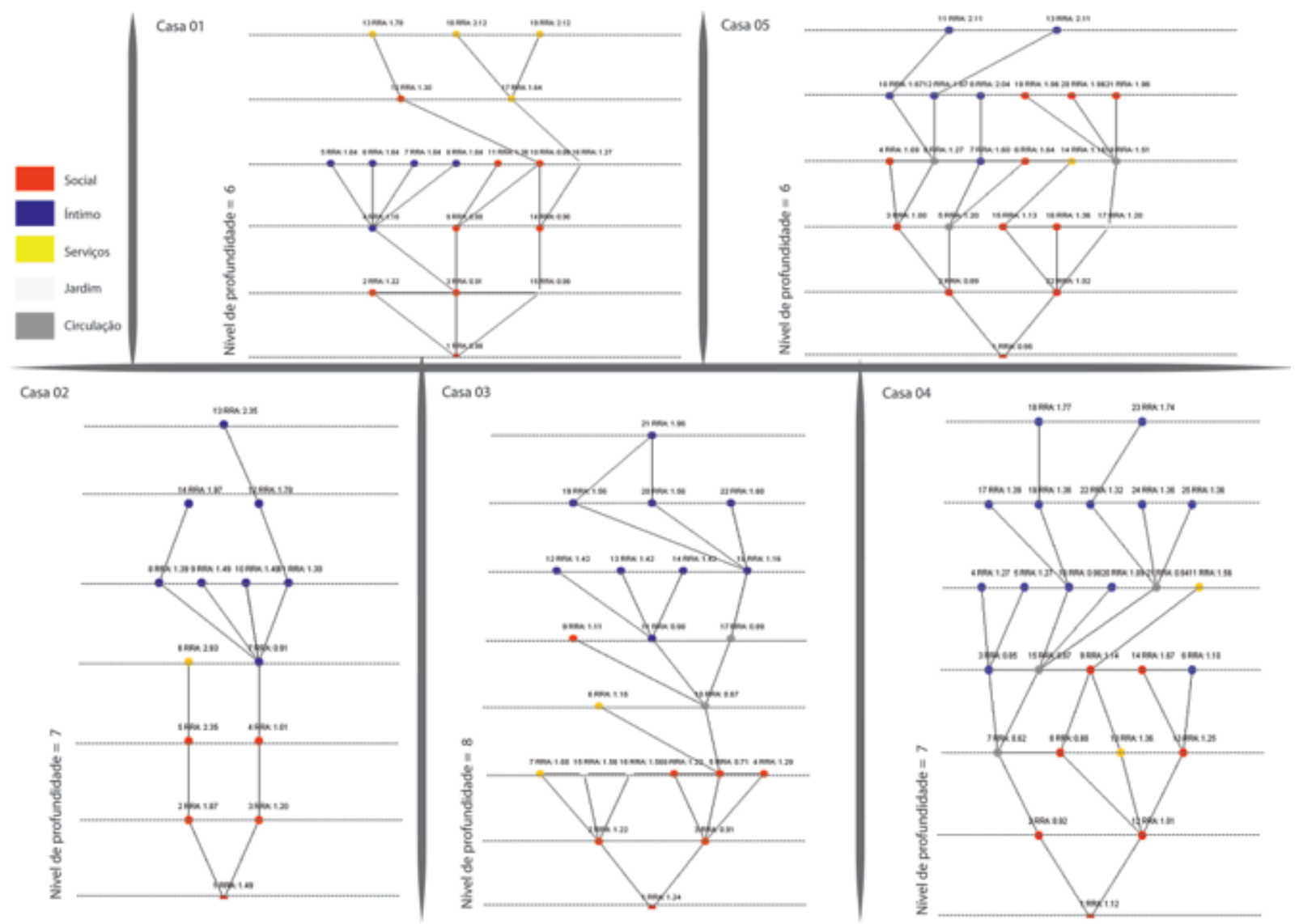

Em geral, pode-se afirmar que as zonas sociais apresentam um melhor desempenho térmico do que as zonas íntimas, ao mesmo tempo em que as zonas sociais são as mais conectadas e integradas considerando a maior parte das simulações de sintaxe realizadas na pesquisa, Figura 4 e Figura 13.

Figura 13: Média de valores de conectividade por zona para análise de visibilidade.

\section{Conectividade Média (VGA)}

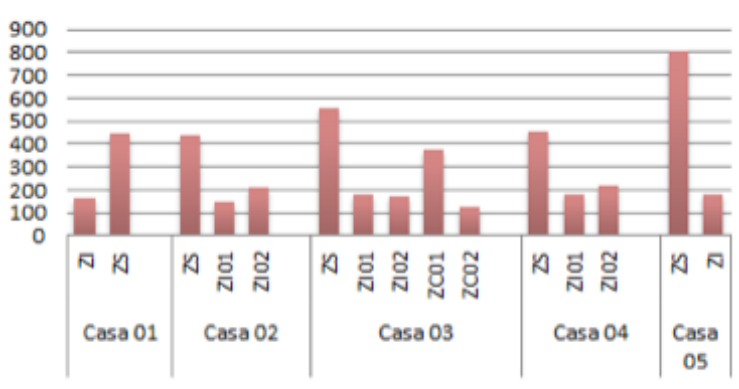

w Conectividade/vis ibilidade (VGA)

Considerando a relação entre medidas de Sintaxe Espacial, tais como conectividade e integração e as taxas de troca de ar (ach), é interessante notar que as correlações encontradas são muito baixas, conforme Figura 14 e Figura 15.
Figura 14: Conectividade (visibilidade) versus média anual de taxas de troca de ar por hora (ach) para cada zona.

\section{Conectividade X Trocas de ar (ach)}

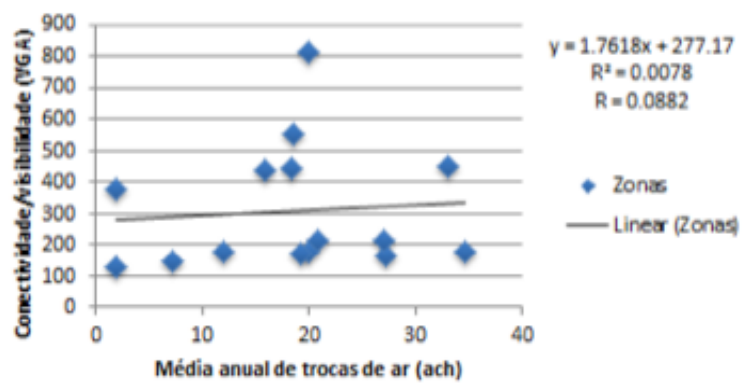

Figura 15: Integração (permeabilidade) versus média anual de taxas de troca de ar por hora (ach) para cada zona.

\section{Integração X Trocas de ar (ach)}

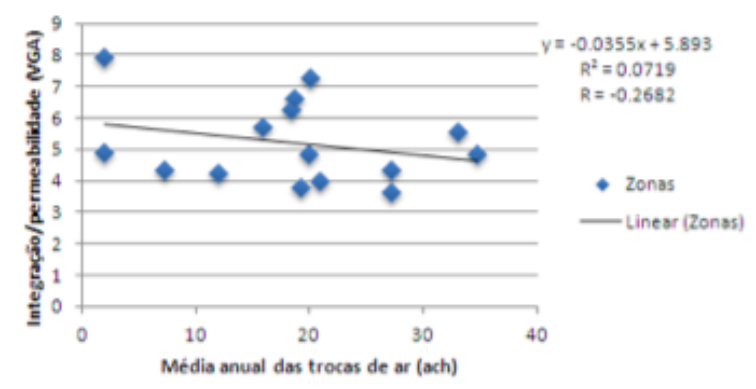

A correlação encontrada entre valores de Conectividade (visibilidade) e taxas anuais de troca de ar (ach) é 0.088, muito fraca. Para a correlação entre os valores de Integração (visibilidade) e taxas 
anuais de troca de ar (ach) foi encontrado -0.17, igualmente muito fraca. Entretanto, considerando os valores para Integração (permeabilidade), a correlação é um pouco mais alta, $-0,27$, porém, não tão relevante.

\section{Conclusões}

O padrão identificado entre baixo índice de fechamento, maiores taxas de ventilação, alta compacidade, e melhor desempenho térmico é interessante porque pode levar à conclusão de que é possível ter-se edificações mais compactas com menos divisões internas (e então menores valores de índice de fechamento) e melhor desempenho térmico. No entanto, por outro lado, quanto mais espalhada seja a planta do projeto,o mesmo deveria apresentarvalores ainda menores de índice de fechamento tendo em vista uma maior taxa de infiltração de ar, ou trocas de ar por zona.

Foi também observado que quanto mais rasos os sistemas configuracionais, melhor o desempenho térmico das edificações, ou menor o número de Graus-hora $>26^{\circ} \mathrm{C}$. Em geral, os modelos com dois pavimentos são mais profundos que os modelos com apenas um pavimento. Talvez a resposta para melhores métodos de projetação de edificações naturalmente ventiladas, os quais almejem melhor desempenho térmico, seriam sistemas mais rasos, porém com menores índices de fechamento, e alta conectividade e integração visual.

A amostra analisada é ainda pequena para extraíremse conclusões generalizadas acerca das influências mútuas entre distribuição espacial e análise térmica em edificações, considerando-se que apenas cinco casos foram analisados. Entretanto, os autores da pesquisa trabalham no sentido de expandir a amostra tendo em vista resultados mais representativos e consistentes.

\section{Referências}

BECK; Turkienicz.Visibility andPermeability. Complementary Syntactical Attributes of Wayfinding. 7th International Space SyntaxSymposium. Sweden, 2009 .

ELETROBRAS/PROCEL.Manual RTQ-R-T2(Versão em desenvolvimento). Florianópolis, Laboratório de Eficiência Energética em Edificações (LABEE/UFSC), 2009.

GOULART, Solange; LAMBERTS, Roberto; FIRMINO, Samanta. Dados climáticos para projeto e avaliação energética de edificações para 14 cidades brasileiras. 2 ed. Florianópolis: Núcleo de Pesquisa em Construção/UFSC, 1998.
HANSON, Julienne.Decoding Homes and Houses. Cambridge, Cambridge University Press, 1998.

ENERGYPLUS.Input Output Reference - The Encyclopedic Reference to EnergyPlus Input and Output. University of Illinois and Ernest Orlando Lawrence Berkley National Laboratory, 2012.

HILLIER, Bill \& HANSON, Julliene. The social logic of space.Cambridge,Cambridge University Press,1984.

HOLANDA, Frederico de (Org.). Arquitetura \& Urbanidade. Brasília, FRBH Edições, 2011.

LU; PEPONIS; ZIMRING.Targeted Visibility Analysis in Buildings Correlating Targeted Visibility Analysis with Distribution of People and Their Interactions within an Intensive Care Unit. 7th International Space Syntax Symposium.Sweden, 2009.

PREFEITURA MUNICIPAL DE NATAL. Secretaria Municipaldo Meio Ambiente e Urbanismo. Instrumentos do Ordenamento Urbano de Natal. Natal, Departamento de Informação, Pesquisa e Estatística, 2009.

SORGATO, Marcio José. Desempenho térmico de edificações residenciais unifamiliares ventiladas naturalmente. 2009. 216 f. Dissertação (Mestrado em Engenharia Civil) - UFSC, Florianópolis, 2009.

TURNER; Alasdair.Analysing the visual dynamics of spatial morphology.Environment and Planning B: Planning a nd Design, v. 30, p. 657-676, 2003.

TURNER; DOXA; O'SULLIVAN; PENN. From isovists to visibility graphs: a methodology for the analysis of architectural space. Environment and Planning B: Planning and Design, v. 28, p. 103-121, 2001.

VERSAGE, Rogério de Souza. Ventilação natural e desempenho térmico de edifícios verticais multifamiliares em Campo Grande, MS. 2009. 96 f. Dissertação (Mestrado em Engenharia Civil) - UFSC, Florianópolis, 2009. 